\title{
Simulation Experiment Platform of Electric Traction Motor Drive System Vector Control Based on Saber
}

\author{
Lan Ban, Can Yang
}

Tianjin College, University of Science and Technology Beijing, Tianjin, China

Keywords: traction motor, driving system, vector control, saber simulation

\begin{abstract}
In order to verify the shortages of electric traction motor drive system, the decoupling model of asynchronous machine is derived from the mathematical model in the three-phase static coordinate system through the vector coordinate transformation. Building the mathematical model of the asynchronous machine with stator current and rotor flux as state variables, the model of flux estimation, slip frequency calculators and decoupling controller are derived from the state equation of induction motor. According to the traction motor, power drive and control system model, establishing simulation model of the tractor motor driving system based on rotor field oriented with saber. Do the simulation of the $110 \mathrm{KW}$ traction motor using of the established simulation model of the electrical system, the characteristics of asynchronous machine are given in the simulation results under different working conditions which provides theoretical reference for real vehicle design.
\end{abstract}

\section{Introduction}

Electrical driving mine car includes three key techniques: the battery technology, Drive motor and its control technique and energy management system [1]. The motor drive system is the core part of the electric drive vehicle and the AC asynchronous machine is in a dominate position in the driving system. The research and develop of advanced induction motor can effectively promote mining vehicle's dynamic property, economy, security and reliability performance. The article is mainly focused on vehicle traction motor drive system of vector control experiment platform is established.

\section{Modeling and Simulation}

\subsection{Decoupling control model}

If $d-p$ coordinate system of $d$ axis rules for the direction of the total rotor flux, and called the magnetization axis; such d-p coordinate system becomes to the rotor field-oriented coordinate system, coordinate axis in synchronous rotating angular velocity $\omega_{s}$. At this time on the q shaft rotor flux component is zero, namely $\mathrm{d}$ axis is pure excitation current component, $\mathrm{q}$ for pure torque shaft current component. State equation of induction motor under $\mathrm{d}-\mathrm{q}$ coordinate system can be expressed as the general form:

$$
P\left[\begin{array}{c}
i_{d s} \\
i_{q s} \\
\Psi_{d r} \\
\Psi_{q r}
\end{array}\right]=\left[\begin{array}{cccc}
-\left[\frac{R_{s}}{\sigma L_{s}}+\frac{(1-\sigma) R_{r}}{\sigma L_{r}}\right] & \omega_{s} & \frac{L_{m} R_{r}}{\sigma L_{s} L_{r}^{2}} & \frac{L_{m}}{\sigma L_{s} L_{r}} \omega_{r} \\
-\omega_{s} & -\left[\frac{R_{s}}{\sigma L_{s}}+\frac{(1-\sigma) R_{r}}{\sigma L_{r}}\right] & -\frac{L_{m}}{\sigma L_{s} L_{r}} \omega_{r} & \frac{L_{m} R_{r}}{\sigma L_{s} L_{r}^{2}} \\
\frac{L_{m} R_{r}}{L_{r}} & 0 & -\frac{R_{r}}{L_{r}} & \omega_{s e} \\
0 & \frac{L_{m} R_{r}}{L_{r}} & -\omega_{s e} & -\frac{R_{r}}{L_{r}}
\end{array}\right]\left[\begin{array}{c}
i_{d s} \\
i_{q s} \\
\Psi_{d r} \\
\Psi_{q r}
\end{array}\right]+\frac{1}{\sigma L_{s}}\left[\begin{array}{c}
U_{d s} \\
U_{q s} \\
0 \\
o
\end{array}\right]
$$

According to the rotor magnetic field orientation, There are $\Psi_{d r}=\Psi_{r}, \Psi_{q r}=0$ will more stylized Jane available: 


$$
\begin{aligned}
& \Psi_{d r}=\frac{L_{m} i_{d s}}{\frac{L_{r}}{R_{r}} S+1} \\
& \omega_{s e}=\frac{L_{m} R_{r}}{L_{r}} \cdot \frac{i_{q s}}{\Psi_{d r}} \\
& \omega_{s}=\omega_{r}+\omega_{s e} \\
& \Delta u_{d s}=-\omega_{s} \cdot \sigma \cdot L_{s} \cdot i_{q s} \\
& \Delta u_{q s}=\omega_{s} \cdot \sigma \cdot L_{s} \cdot i_{d s}+\omega_{s} \cdot \frac{L_{m}}{L_{r}} \cdot \Psi_{r}
\end{aligned}
$$

At this moment, has been formed between A and B single variable system, however, for output $\omega_{s}$, coupling between. $\omega_{r}, i_{d s}, i_{q s}$. That is to say, the only current vector control of excitation and torque components, the decoupling between the did not realize the decoupling of the whole system $^{[2]}$.

According to the above three formulas were established flux estimation, slip frequency calculators and decoupling controller Saber simulation model.

\subsection{The torque and flux linkage control model}

The Saber with flux closed-loop structure of the controller system model as shown in Fig. 4, consists of two current closed-loop vector control, as long as the closed loop stability, stator current of motor is controlled. To this point in the electric wheel dump truck start stage, especially when the slope is very important. Early stage of the vehicle is a state of low speed high torque, If current can't stable control, current fluctuations can occur easily, and thus lead to the phenomenon of torque ripple. The flux regulator circuit for the stator flux linkage of motor control

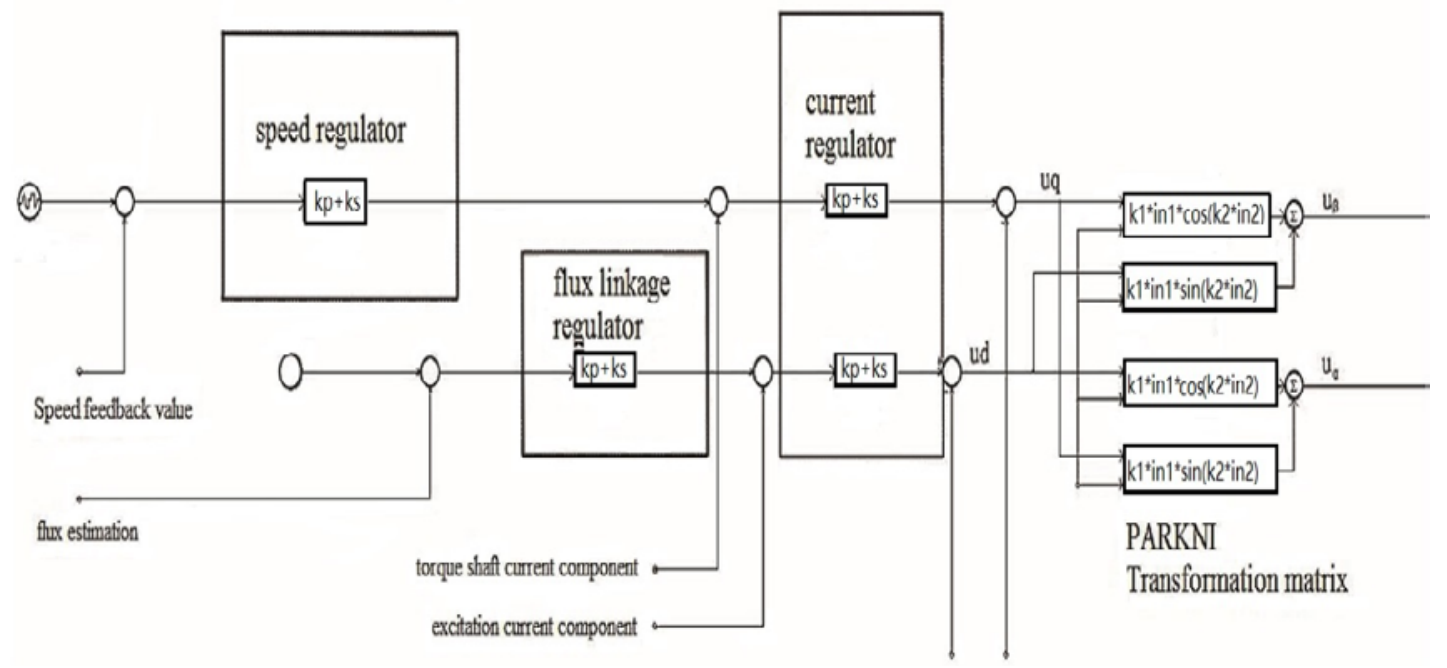

Fig. 1 Transfer torque current and excitation current vector control system independent PI regulating structure

\section{The Feasibility of Vector Control System Simulation Model Validation}

Using the built in front of the traction motor vector control system for the known parameters of the model simulation, observe the simulation results, check out the feasibility and accuracy of the model. Selection of the motor parameters as shown in Table 1 . The motor parameters into the electrical system in the simulation model of the global variable definition module, the dc bus voltage of $690 \mathrm{~V}$, sampling period of $10 \mathrm{KHZ}$, after trial and error method is used to set the controller parameters are shown in Table 2, two of the same current controller parameters. 
Table 1 Electric machine parameter

\begin{tabular}{|c|c|c|c|c|c|c|c|}
\hline Rs & $\mathrm{Rr}$ & Lls & Llr & $\mathrm{Lm}$ & $\mathrm{J}$ & $\mathrm{P}$ & $\mathrm{Pn}$ \\
\hline $\begin{array}{c}3.712 \\
\Omega\end{array}$ & $\begin{array}{c}2.789 \\
\Omega\end{array}$ & $\begin{array}{c}16.37 \\
\mathrm{mH}\end{array}$ & $\begin{array}{c}16.37 \\
\mathrm{mH}\end{array}$ & $\begin{array}{c}294.8 \\
\mathrm{mH}\end{array}$ & $\begin{array}{l}0.003 \\
\mathrm{~kg} \cdot \mathrm{m}^{2}\end{array}$ & 0.0001 & 2 \\
\hline \multicolumn{8}{|c|}{ Table 2 The controller parameters } \\
\hline \multicolumn{2}{|c|}{ argument } & \multicolumn{2}{|c|}{ speed regulator } & \multicolumn{2}{|c|}{ Flux regulator } & \multicolumn{2}{|c|}{ current controller } \\
\hline \multicolumn{2}{|c|}{ Kp } & \multicolumn{2}{|c|}{0.15} & \multicolumn{2}{|c|}{50} & \multicolumn{2}{|c|}{200} \\
\hline \multicolumn{2}{|c|}{$\mathrm{Ki}$} & \multicolumn{2}{|c|}{4} & \multicolumn{2}{|c|}{500} & \multicolumn{2}{|c|}{2000} \\
\hline
\end{tabular}

Using Saber $\backslash$ Scope window to observe the waveform:

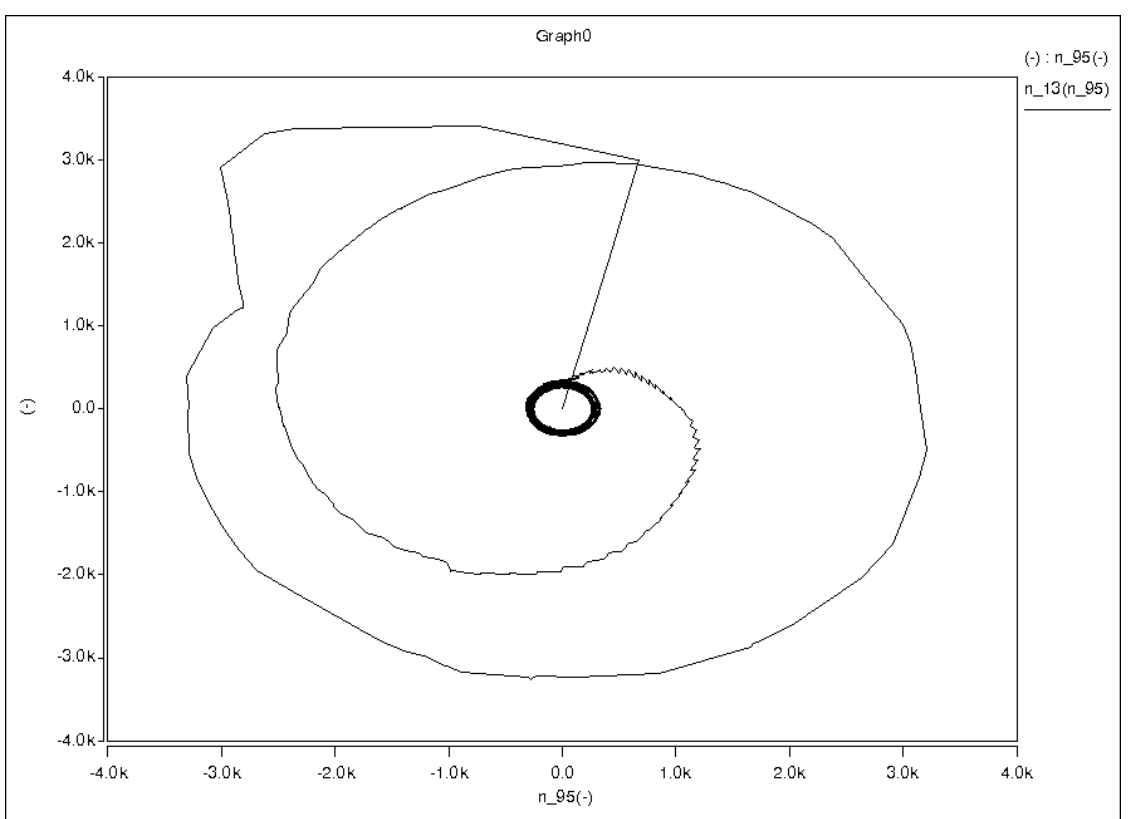

Fig. 2 flux trajectory locus of no excitation control

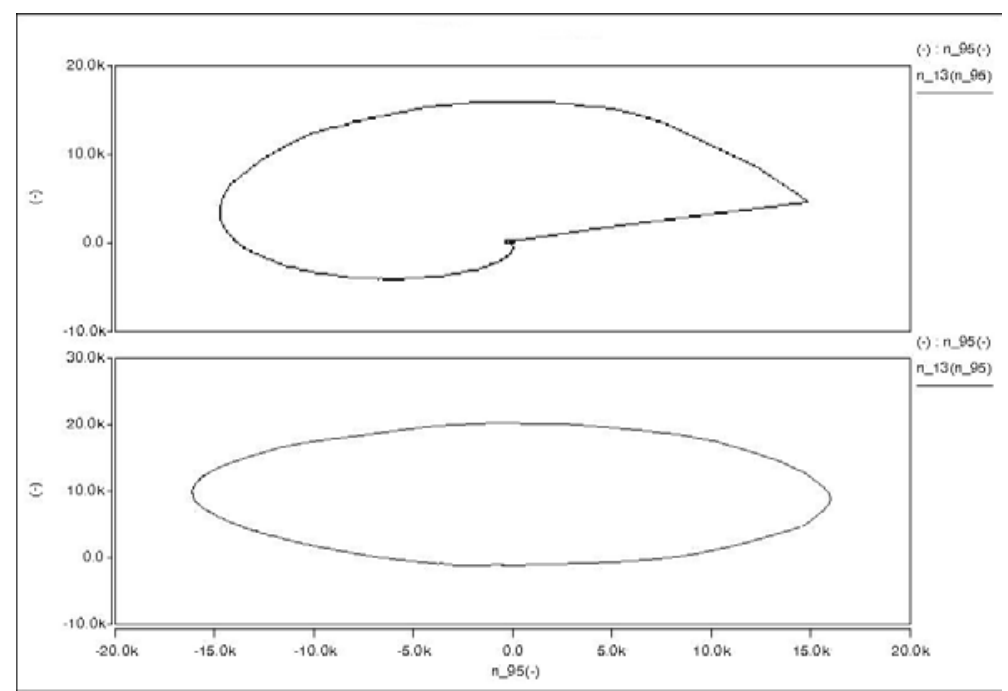

Fig. 3 Flux trajectory locus of Excitation loop before and after improvemen 


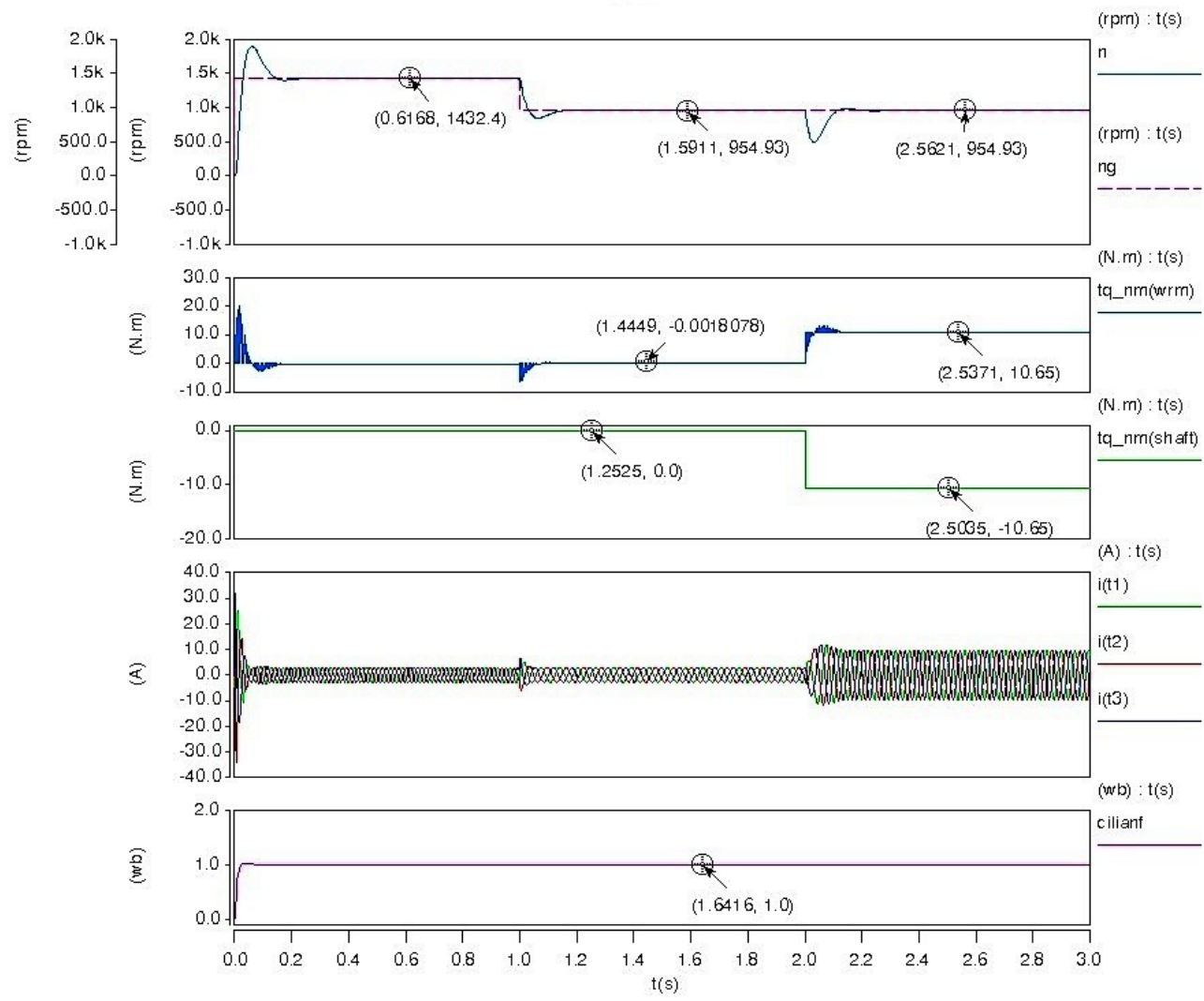

Fig. 4 Variable speed motor load conditions when the motor speed, torque, current and flux linkage

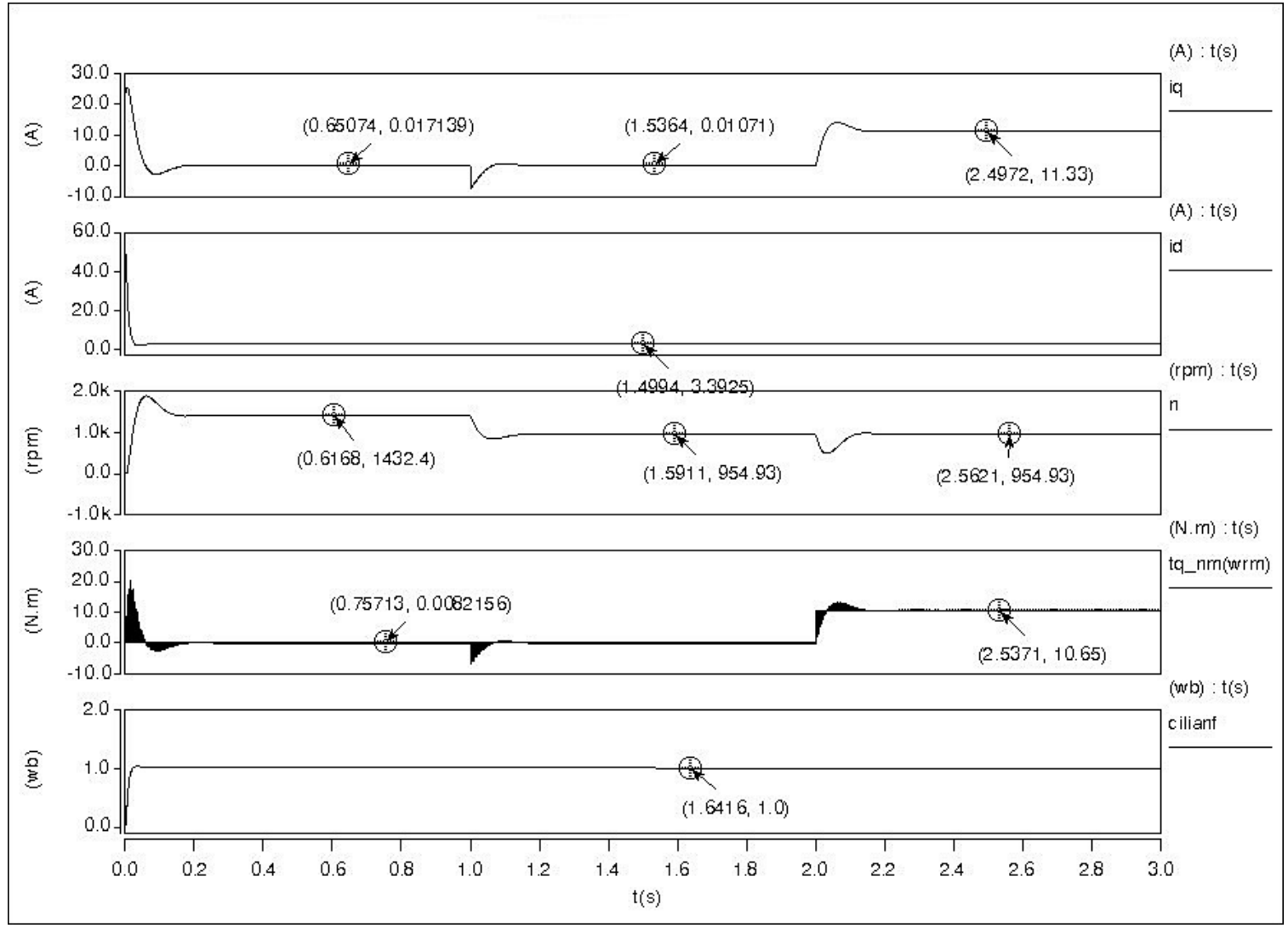

Fig. 5 The realization of the torque current component $i_{q}$ and Excitation current component $i_{d}$ decoupling 


\section{Conclusion}

Building a model of traction motor drive system, firstly according to the principle of vector coordinate transformation to build the simulation model of CLARK and PARK and its inverse matrix. From the three-phase ac asynchronous motor in d-p coordinates system on the dynamic mathematical model is based on the rotor field-oriented vector control system of flux estimation, slip frequency calculators and mathematical model of the decoupling controller and to build the simulation model. Analyzes the rotor field oriented vector control theory and based on the advantages of speed and current double closed loop PI control, the control system of PI adjustment model is established; Establishing simulation model of the tractor motor driving system based on rotor field oriented with saber. Do the simulation of the $110 \mathrm{KW}$ traction motor using of the established simulation model of the electrical system, the characteristics of asynchronous machine are given in the simulation results under different working conditions which provides theoretical reference for real vehicle design.

\section{References}

[1] Zhuang Hongchao, Gao Haibo, Deng Zongquan, Ding Liang, Liu Zhen. A review of heavy-duty legged robots [J]. Science China (Technological Sciences).2014-02

[2] A.Mezouar, M.k. Fellab, S.Hadjeri. Adaptive sliding mode observer for sensorless induction motor-drive using two-time scales [J]. Simulaiton Modelling Practice and Theory.2008, 16(9): 1323-1336.

[3] Martin LaMonica.GE takes giant hybird dump truck for a ride [J/OL]. (2008-4-23). 